\title{
E-LEARNING CHALLENGES FROM THE STUDENTS' POINT OF VIEW
}

\author{
Daiva Rimkuviene, Vytautas Magnus University, Lithuania, Anna Vintere, Latvia
}

University of Life Sciences and Technologies, Latvia, Eve Aruvee, Estonian University of Life

Sciences, Estonia

\section{Abstract}

E-learning has become mandatory at all levels of educational institutions due to the coronavirus pandemic. This paper analyses the learning difficulties that university students have encountered as a result of this changed situation. Empirical research includes a survey of students at three Baltic universities: Latvia University of Life Sciences and Technologies (LLU), Vytautas Magnus University (VMU) and Estonian University of Life Sciences (EMÜ). The aim of our article is to compare opinions on the challenges faced by students of Baltic States during mandatory remote learning. The results of this study revealed that there were no statistically significant differences between respondents in the countries participating in the survey in terms of the opinions expressed on the availability of appropriate hardware, communication with teacher and interaction with classmates and difficulty focusing on remote studies. Students who prefer face to face learning style mentioned difficulties in paying attention to studies, In addition, the majority of respondents indicated that they often had problems communicating with teachers. It was found that not only achieving learning outcomes, implementing practical works, and the volume of study works caused challenges but also lack of digital skills and interaction with classmates.

\section{Introduction}

The COVID-19 pandemic outbreak forced many educational units to suspend typical faceto-face classes to ensure the safety of students, lecturers (Mukhtar et al.; 2020; Baczek et al., 2021; Rahiem, 2021). Universities are struggling to find options to deal with this challenging situation.

Modern ICT provide enormous opportunities for effective communication (Bravo-Agapito et al., 2021). E-learning programmes and courses were already available for people who were mentally and economically ready for such learning (Popovici \& Mironov, 2015). 
Although many academic units of Universities in Baltic countries have also started blended or online learning, still a lot of them are stuck with old procedures, that is, they follow the traditional set up of face-to-face lectures in classrooms. Baltic universities remote learning in Moodle environment took many years to be implemented. However, the majority of taught courses integrated only the presentation of the educational material. Part of the courses was adapted to be learnt through a blended learning approach when students could take part of the course in classrooms. The assessments of the students were performed only at the University. However, it should be noted that students had an opportunity to choose different study forms. Usually, both teachers and students preferred face-to-face communication as a more effective way to communicate information.

The sudden shift to full online instruction led universities members to adjust their teaching plans, teaching styles and assessment methods (Orlov et al., 2021). In the 2020 Spring semester, both university teachers and students faced many problems. There was an urgent demand for computer equipment, teachers had to learn to deliver lectures, and students had to comprehend online material. Lectures were taught through various video conferencing software, as for example, AdobeConnect, BigBlueButtons (BBB), MsTeams, and Zoom. There were cases when the systems crashed due to the high number of connected users. Teachers of various courses experienced problems with the material presentation. For example, for teaching mathematics, the usual practice is to present solutions to problems on the board. For social sciences, it is necessary to ensure the opportunity for students to communicate and develop discussions. Students also faced the challenge to quickly adapt to the "new normal" in a higher education setting (Lapitan et al., 2021; Toquero, 2021). It is evident that students found a new teaching method unusual and causing many learning difficulties. Looking at the challenges of remote learning, technological knowledge, communication skills and time management skills are the ones that determine the effectiveness of remote learning (Martin et al., 2020).

For the Autumn semester, the university community has prepared better. As distance learning was already expected, universities were provided with the necessary equipment and training in advance. VMU, LLU, EMÜ use Moodle as the main learning environment. MsTeams is recommended as the main platform for video conferencing software at VMU. Studies at LLU were provided remotely using the video conferencing system BigBlueButton (BBB) integrated in the Moodle system. The Zoom platform was often used for individual consultations and additional classes, depending on its accessibility to teachers. The Zoom is most commonly used for lectures and communication at EMÜ. The work in the Autumn semester has started in the classrooms by keeping a safe distance. However, due to the dramatic deterioration of the situation in the country, since the middle 
of October in Lithuania and the middle of December in Estonia, Baltic countries has returned to remote learning. Remote learning was continued in the 2021 Spring semester.

Literature sources provide a number of analytical articles on learning challenges during learning at home and highlight certain factors such as levels of motivation, teachers' knowledge of e-learning techniques and pedagogy, and the structured learning environment influencing student satisfaction with their remote learning experience during the COVID19 pandemic (Baber, 2020). While understanding that this way of teaching is forced and temporary, it is useful to know what challenges students have faced and what suggestions they make. The aim of our article is to compare opinions on the challenges faced by students of Baltic States during remote learning.

\section{Materials and methods}

Empirical research includes a survey of students at three Baltic universities: Latvia University of Life Sciences and Technologies, Vytautas Magnus University and Estonian University of Life Sciences on the challenges and benefits of remote learning during the COVID-19 pandemic. The questionnaires are available at: https://ej.uz/ATT_S (in Latvian), https://ej.uz/estudies_EE (in Estonian) and https://ej.uz/estudies_LT (in Lithuanian). 387 students from various specialities participated in this research.

The questionnaire included questions related to the students' attitudes towards challenges posed by remote learning. Students had four answers to choose from: never (1), rarely (2), often (3), and always (4). Students were also asked for suggestions to improve remote learning.

Respondents' answers are analysed from two perspectives: (a) Are there differences between countries? (b) Is there a difference, depending on learning style preferences?

As well, Principal Component Analysis (PCA) was performed in order to observe an underlying structure in a complex system of variables.

To perform data analysis, the Cronbach's alpha test was used for assessing the reliability of the questionnaire, Kruskal-Wallis test and Wilcoxon test - for comparing between groups, as well as Tukey test - for pairwise comparison. A statistically significant value of $\mathrm{P}<0.05$ was considered.

The data were analysed using the statistical package $\mathrm{R}$ version 4.0.3 (R Core Team, 2020). 


\section{Results}

The data analysis showed that 266 fully completed questionnaires were submitted. 91 Estonian, 54 Lithuanian, and 121 Latvian students completed the questionnaire.

Table 1 presents the distribution of respondents' opinions on the learning style preferences. Having analysed the preferences of students' learning style, statistically significant differences by country were identified (chi-square $=24.18, \mathrm{p}<0.001$ ). Even $61.5 \%$ of Estonian students prefer face to face with a teacher learning style. $31.5 \%$ of Lithuanian respondents indicated that they prefer e-learning and a similar proportion (29.6\%) mentioned that they prefer face to face learning.

Table 1: $\quad$ Learning style preferences

\begin{tabular}{lccccc}
\hline & $\begin{array}{c}\text { learning face to face } \\
\text { with a teacher }\end{array}$ & $\begin{array}{c}\text { e-learning/ remote } \\
\text { learning }\end{array}$ & $\begin{array}{c}\text { learning in a } \\
\text { group }\end{array}$ & $\begin{array}{c}\text { learning by } \\
\text { myself }\end{array}$ & other \\
\hline Estonia & $61.5 \%$ & $18.7 \%$ & $12.1 \%$ & $1.1 \%$ & $6.6 \%$ \\
Latvia & $43.0 \%$ & $24.8 \%$ & $19.8 \%$ & $9.9 \%$ & $2.5 \%$ \\
Lithuania & $29.6 \%$ & $31.5 \%$ & $16.7 \%$ & $14.8 \%$ & $7.4 \%$ \\
\hline
\end{tabular}

In order to find out what problems students encountered when studying remotely, we asked 11 questions (Cronbach's alpha $=0.77$ ). The average response rates are shown in Table 2. Letters $a, b$ and $c$ means that these groups are different, and $a b$ indicates that there is no difference in the groups. Regarding the results presented in the table, it can be seen that the answers of Lithuanian students fall into the group $a$. That is, they were more likely to say that they rarely or never encountered the problems mentioned. There were no statistically significant differences between the opinions of students from different countries when answering the questions about Availability of appropriate hardware / smart devices / software at home, Communication with teachers, Personal motivation/desire to complete assignments and Difficulty focusing or paying attention to remote studies.

The most contrasting opinions were found in the choice of answers to the questions on Digital skills to use distance learning platforms/tools offered by teachers. This lack of digital skills was mainly experienced by Latvian students. $62.0 \%$ of students noted that they had problems with the platforms offered by the teachers.

Unfortunately, the results of the analysis show that most respondents indicated that they often encountered problems in communicating with teachers. In this case, there were no statistically significant differences in the analyses of all countries. Moreover, the Latvian students have indicated that they more often faced challenges on the Implementation of practical / laboratory work / practice, Lithuanian students on the Difficulty of focusing or paying attention to remote studies, and Estonian respondents on the Volume of study works. Latvian and Estonian students encountered challenges regarding the Availability of 
appropriate hardware / smart devices / software at home the least, while Lithuanian students encountered challenges regarding Digital skills to use remote learning platforms / tools offered by teachers.

Table 2: $\quad$ Challenges posed by remote learning. Questionnaire results by countries

\begin{tabular}{|c|c|c|c|c|c|}
\hline & $\begin{array}{l}\text { Latvia } \\
\text { mean } \\
\text { (group) }\end{array}$ & $\begin{array}{l}\text { Lithuania } \\
\text { mean } \\
\text { (group) }\end{array}$ & $\begin{array}{l}\text { Estonia } \\
\text { mean } \\
\text { (group) }\end{array}$ & $\begin{array}{l}\text { Kruskal- } \\
\text { Wallis }\end{array}$ & p-value \\
\hline $\begin{array}{l}\text { Q1. Availability of information on e- } \\
\text { learning opportunities / remote } \\
\text { study process }\end{array}$ & $2.47(b)$ & 2.04 (a) & $2.19(a b)$ & 11.28 & 0.003 \\
\hline Q2. Volume of study works & $2.32(a)$ & $2.41(a)$ & $2.93(b)$ & 27.29 & $<0.001$ \\
\hline $\begin{array}{l}\text { Q3. Implementation of practical / } \\
\text { laboratory work / practice }\end{array}$ & $2.80(b)$ & $2.04(a)$ & 2.10 (a) & 32.49 & $<0.001$ \\
\hline $\begin{array}{l}\text { Q4. To achieve the study results } \\
\text { provided for in the study courses }\end{array}$ & $2.73(b)$ & 2.06 (a) & 2.07 (a) & 28.60 & $<0.001$ \\
\hline $\begin{array}{l}\text { Q5. Availability of appropriate } \\
\text { hardware / smart devices / software } \\
\text { at home }\end{array}$ & $2.12(a)$ & 2.17 (a) & 1.97 (a) & 2.91 & 0.234 \\
\hline Q6. Internet connection instability & $2.58(b)$ & 2.24 (a) & 2.57 (b) & 0.23 & 0.013 \\
\hline $\begin{array}{l}\text { Q7. Difficulty focusing or paying } \\
\text { attention to remote studies }\end{array}$ & $2.72(a)$ & $2.83(\mathrm{a})$ & $2.74(a)$ & 1.05 & 0.591 \\
\hline $\begin{array}{l}\text { Q8. Personal motivation/desire to } \\
\text { complete assignments }\end{array}$ & $2.63(a)$ & 2.57 (a) & $2.63(a)$ & 0.14 & 0.931 \\
\hline $\begin{array}{l}\text { Q9. Digital skills to use distance } \\
\text { learning platforms / tools offered by } \\
\text { teachers }\end{array}$ & $2.75(c)$ & $1.98(a)$ & 2.40 (b) & 28.62 & $<0.001$ \\
\hline Q10. Communication with teachers & $2.91(\mathrm{a})$ & $2.83(a)$ & $2.96(a)$ & 0.81 & 0.668 \\
\hline Q11. Interaction with classmates & $2.60(b)$ & 2.25 (a) & $2.48(a b)$ & 6.38 & 0.042 \\
\hline
\end{tabular}

It was also examined whether the problems encountered by students during remote learning are dependent on learning style preferences. Wilcoxon test $(\mathrm{W}=5863, \mathrm{p}<0.001)$ has shown there is a statistically significant difference in assessing Difficulty focusing or paying attention to remote studies between students, who prefer face to face learning style and the ones who prefer e-learning style. It is obvious that those who prefer learning face to face have faced more difficulties in Focusing attention on studies.

The performed Principal Component Analysis (PCA) shows that when all variables are included, three components explain only $54 \%$ of the variation and four components explain 63\%. When the variables Q1-Q6, Q9 and Q11 are included, three components explain 68\% of the variation, four - 78\%. Therefore, the more detailed analysis was performed by including only the aforementioned variables. Figure 1 presents the graphic interpretation of $\cos 2$ of variables. A high $\cos 2$ indicates a good representation of the variable on the principal component. 
The first principal component Dim1 explains $43 \%$ of the variation and is moderately correlated with six of the original variables (Figure 1a): Q3 - Implementation of practical / laboratory work / practice (0.42), Q4 - Achieving the study results provided for in the study courses (0.44), Q11 - Interaction with classmates (0.40), Q1 - Availability of information on e-learning opportunities / remote study process (0.38), Q6 - Personal motivation/desire to complete assignments (0.38), Q9 - Digital skills to use distance learning platforms / tools offered by teachers. This component may be described as flexible adaptation.

The second principal component (Dim2) explains $13 \%$ of the variation and is highly correlated with Q2 - Volume of study works (0.74)

The third principal component (Dim3) explains $12 \%$ of the variation and is highly correlated with Q5 - Availability of appropriate hardware / smart devices / software at home (0.87).

(a)

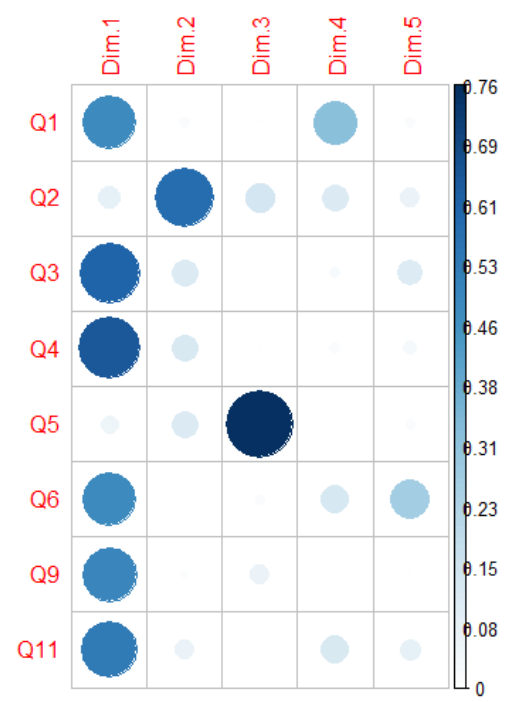

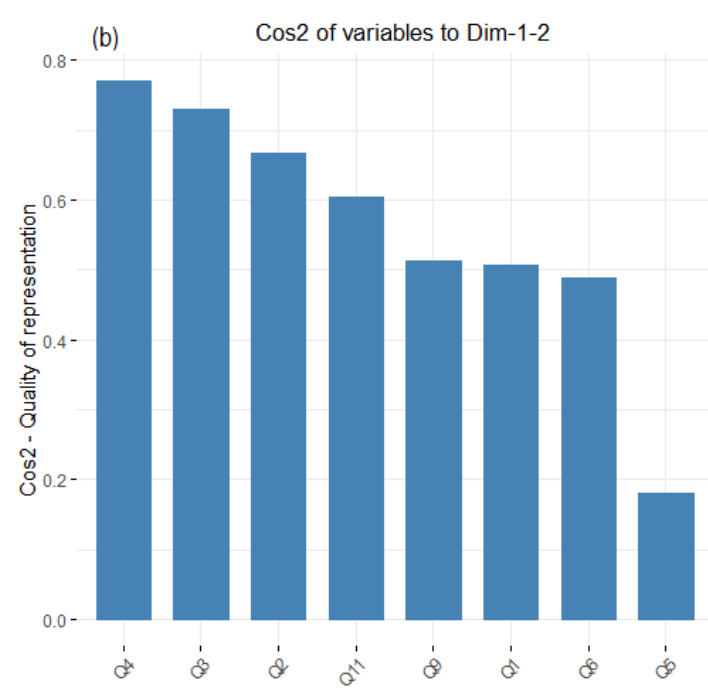

Figure 1. The quality of representation of the variables on factor map: graphic interpretation of $\cos 2$ of variables

As can be seen in Figure 1 (b), the most important variables are related to the main learning challenges Q4, Q3, Q2 and Q11, i.e. how to achieve favourable learning outcomes despite changes in the learning environment. The challenge of the same significance is Interaction with classmates.

Finally, it was relevant to find out what recommendations have been made by the students for the improvement of remote learning. Only $49.6 \%$ of Latvian, $51.9 \%$ of Lithuanian, $67.3 \%$ of Estonian respondents gave answer to the question: "In your opinion, what is needed (what e-learning improvements, improvements, etc.) to make e-learning more accessible, efficient and ensure higher quality of education?" 
$20.6 \%$ of Latvian, $12.9 \%$ of Lithuanian and $5 \%$ of Estonian students answered, everything is satisfactory and the study materials are enough. In addition, some even point out that only the willpower is needed to learn and master everything. $7.9 \%$ of respondents indicated that they are against distance learning in general and want to resume full-time studies. It should be noted that opinions vary. Some students would prefer pre-recorded classes, thus avoiding possible technical problems. Others prefer live discussions and the opportunity to ask questions.

Respondents note that not all teachers are provided with quality equipment such as good microphones and graphic tablets. They also emphasise the need to improve the assessment of given tasks. They appreciate the changed and thus broader possibilities of teaching methods and suggest more varied ways of presenting material and tasks. In addition, they would like to be provided with more descriptions in their mother tongue after, for example, reviewing online entries, as not all specific subject terms are easy to perceive. pointed to the need to ensure better operation of the BBB server and Internet connection, as there had been various cases (especially at the beginning of remote studies) when video lectures lost their Internet connection, that nothing could be understood from the lectures and they had to be moved. Sometimes the e-learning system got a little stuck, prevented from connecting to the BBB or even thrown out of it. But $6.3 \%$ of responses of Latvian students indicated flaws in the Moodle e-learning platform related to file upload, deletion / retention of previous versions and their availability to teachers, etc.- During the tests, which were placed in e-studies and were given a set time, the students had to wait a long time until the next task appeared. They also had to wait a long time for the study materials placed in estudies to open. Students also recommend improving the interface of the Moodle system, for example, using an online platform with integrated microphone push-to-talk.

Admittedly, some of the answers (11.1\% of Latvian, 16.7\% of Lithuanian, $10.9 \%$ of Estonian respondents) also include teachers' knowledge of e-learning techniques and pedagogy. Students believe that teachers should take advantage of study opportunities and post materials on all topics so that they do not have to use e-mail where something may be lost. They pointed out the need to record lectures with appropriate computer programs so that they can be played, as well as to place lecture presentations in the e-learning system. It would be very helpful for students to have more independent work in all subjects, which would have to be submitted later and evaluated. This would help to focus more on learning. In study subjects where it is necessary to solve tasks, lecturers are advised to show the course of solutions in the course of online lectures, rather than leaving the solution of tasks to students.

Students pointed to the need for more interactive lessons, i.e. to try to involve students more in online lectures, using various tools (quiz, questions, games, etc.). Students would 
also like more group work. In the tests, ask what was taught, because there are subjects in which teachers ask for what they have no idea or little talk about. It would also be necessary for teachers to record all lectures, because teachers speak too fast and the most important is difficult to make notes.

A few quotes are provided:

"More in quantity and more engaging self-study, e. g. more engaging tasks, is needed."

"Taking exams is complicated and very stressful as there is very limited time given and no possibilities to go back to questions."

"To my mind, the attitude towards remote learning of both students and teachers should change. In my personal opinion, remote learning is easier as I can concentrate more at home than in a classroom."

Having analysed the answers of the students, it might be stated that the same challenge of achieving the best learning outcomes remained. As well, there are new challenges, such as problems related to software and hardware, and interaction with classmates.

There are some limitations to our study that should be noted. The most important limitation is the sampling technique used. The research sample was selected in a nonrandom way. It should be noted that no analysis has been carried out with regard to students' subjects, choice of specialisation and year of study. The students were reached remotely and the responses were given on a voluntary basis, thus, the study can only be seen as preliminary and as a possible source for further research.

\section{Conclusions}

Based on the pandemic situation, challenges arise in migrating from a physical classroom to a mandatory remote learning environment. Both teachers and students had to change their teaching and learning habits, style and perspective to e-learning. Students' viewpoints towards the problems they face are not homogenous. Part of the students regards the transition to remote learning as acceptable and convenient. Though, a larger group of respondents would prefer learning face to face with a teacher. The comparison of opinions of respondents from Baltic countries shows no statistically significant differences in the evaluation of the availability of appropriate hardware and software at home, a difficulty of concentrating on studies, communication with teachers, interaction with classmates. Opinions contrasted the most on the problems related to digital skills of using remote learning platforms/tools offered by teachers, which was rated by Latvian students as the most frequent difficulty they encountered. The analysis shows that some of the biggest 
problems are related to regular challenges on how to achieve good learning outcomes and how to perform the given tasks. Problems related to communication with both peers and teachers also emerged. Respondents offered suggestions for improving their studies, which may be useful in the post-epidemic period. These include the need for technical improvement, more interactive classes as well as pre-recorded material, a more structured course in a Moodle environment with several teachers, as well as more engaging tasks. It could be argued that the suggestions made by students are in turn a challenge for teachers, who have a lot of work ahead of them to change their teaching style and adapt to sudden changes in the teaching environment. On the other hand, it will be an incentive to improve the quality of teaching in the future. Remote learning has come to stay.

\section{References}

Baber, H. (2020). Determinants of students' perceived learning outcome and satisfaction in online learning during the pandemic of COVID 19. Journal of Education and e-Learning Research, 7(3), 285-292.

Baczek, M., Zaganczyk-Baczek, M., Szpringer, M., Jaroszynski, A., \& WozakowskaKaplon, B. (2021). Students' perception of online learning during the COVID-19 pandemic: A survey study of polish medical students. Medicine, 100(7). Retrieved from https://journals.lww.com/mdjournal/Fulltext/2021/02190/Students_perception_of_online_learning_during_the.8 7.aspx

Bravo-Agapito, J., Romero, S. J., \& Pamplona, S. (2021). Early prediction of undergraduate student's academic performance in completely online learning: A fiveyear study. Computers in Human Behavior, 115, 106595.

https://doi.org/10.1016/j.chb.2020.106595

Lapitan, L. D., Tiangco, C. E., Sumalinog, D. A. G., Sabarillo, N. S., \& Diaz, J. M. (2021). An effective blended online teaching and learning strategy during the COVID-19 pandemic. Education for Chemical Engineers, 35, 116-131. https://doiorg.ezproxy.vdu.lt:2443/10.1016/j.ece.2021.01.012

Martin, F., Stamper, B., \& Flowers, C. (2020). Examining student perception of reading for online learning: Importance and confidence. Online Learning, 24(2), 38-58.

Mukhtar, K., Javed, K., Arooj, M., \& Sethi, A. (2020). Advantages, Limitations and Recommendations for online learning during COVID-19 pandemic era. Pakistan Journal of Medical Sciences, 36(COVID19-S4). https://doi.org/10.12669/pjms.36.COVID19-S4.2785 
Orlov, G., McKee, D., Berry, J., Boyle, A., DiCiccio, T., Ransom, T., et al. (2021). Learning during the COVID-19 pandemic: It is not who you teach, but how you teach. Economics Letters, 202, 109812. https://doi.org/10.1016/j.econlet.2021.109812

Popovici, A., \& Mironov, C. (2015). Students' perception on using eLearning technologies. Procedia - Social and Behavioral Sciences, 180, 1514-1519. https://doi.org/10.1016/j.sbspro.2015.02.300

R Core Team (2020). R: A language and environment for statistical computing. R Foundation for Statistical Computing, Vienna, Austria. Retrieved from https://www.R-project.org

Rahiem, M. D. H. (2021). Remaining motivated despite the limitations: University students' learning propensity during the COVID-19 pandemic. Children and Youth Services Review, 120, 105802.https://doi.org/10.1016/j.childyouth.2020.105802

Toquero, C. M. (2020). Emergency remote education experiment amid COVID-19 pandemic. IJERI: International Journal of Educational Research and Innovation, 15, 162-176. https://doi.org/10.46661/ijeri.5113 